\title{
Qualidade da água da hemodiálise do Hospital Regional de Ilha Solteira, SP
}

\section{Water quality of hemodialysis of the Regional Hospital of Ilha Solteira, SP}

Calidad del agua de la hemodialisis del Hospital Regional de Ilha Solteira, SP

\author{
Claudinéia Brito dos Santos Scavazini ${ }^{1}$ \\ Juliana Heloisa Pinê Américo-Pinheiro²
}

${ }^{1}$ Mestre em Ciências Ambientais pela Universidade Brasil (UNIVBRASIL). Enfermeira pela Fundação Municipal de Educação e Cultura de Santa Fé do Sul (FUNEC). E-mail: claudineia.brito@bol.com.br, Orcid: https://orcid.org/0000-0003-1838-4033

${ }^{2}$ Doutora em Aquicultura na área de Biologia Aquática pela Universidade Estadual Paulista Júlio de Mesquita Filho (UNESP). Professora titular do Programa de Pós-Graduação Stricto Sensu em Ciências Ambientais da Universidade Brasil (UNIVBRASIL). E-mail: americo.ju@gmail.com, Orcid: http://orcid.org/0000-0001-6252-828X 
Resumo: Na hemodiálise, que é a filtragem das impurezas do sangue por processo terapêutico mecânico ao qual são submetidas pessoas com perda da função renal, é usada grande quantidade de água, que deve ser idealmente pura, livre de quaisquer agentes contaminantes. Em Ilha Solteira, SP, a unidade de hemodiálise possui 21 máquinas para realizar as sessões e atende 83 pacientes. Esta pesquisa visou avaliar a qualidade da água de hemodiálise do Hospital Regional de Ilha Solteira, pela comparação das características apresentadas, e os atuais parâmetros físico-químicos e bacteriológicos da água utilizada no tratamento de pacientes renais, além de observar se os aspectos legais estão sendo cumpridos. A metodologia utilizada foi a pesquisa exploratório-descritiva com busca de informações bibliográficas e documentais com foco em leis ou normas ligadas ao tratamento da água para hemodiálise e coleta de dados microbiológicos e físico-químicos nos registros do setor de hemodiálise do hospital pesquisado nos meses de janeiro a dezembro de 2017. Para a coleta de dados, foram definidos quatro pontos de amostra para análise. Os dados obtidos atenderam o padrão para parâmetro de bactérias heterotróficas. Não foram detectadas impurezas na água observada, entre elas, coliformes termotolerantes. Os resultados físico-químicos mostraram valores compatíveis com a legislação e apontaram bom funcionamento da membrana da osmose reversa, evitando complicações aos pacientes. Palavras-chave: coliformes; condutividade; filtração; função renal.

Abstract: In hemodialysis, which is the filtering of blood impurities by a mechanical therapeutic process to which people with loss of renal function are subjected, a large quantity of water is used, which should be ideally pure, free of any contaminating agents. In Ilha Solteira, SP, Brazil, the hemodialysis unit has 21 machines to perform the sessions and serves 83 patients. This research aimed to assess the quality of hemodialysis water at the Regional Hospital of Ilha Solteira, by comparing the characteristics presented, and the current physical-chemical and bacteriological parameters of the water used in the treatment of renal patients, in addition to observing whether the legal aspects are being complied with. The methodology used was exploratory-descriptive research with search for bibliographic and documentary information focusing on laws and standards related to water treatment for hemodialysis and collection of microbiological and physical-chemical data in the hemodialysis sector records of the hospital studied, from January to December 2017. For data collection, four sample points were defined for analysis. The data obtained met the standard for the parameter of heterotrophic bacteria. No impurities were detected in the water observed, including thermotolerant coliforms. The physical-chemical results showed values compatible with the legislation and indicated a good functioning of the reverse osmosis membrane, avoiding complications to patients.

Keywords: pavement management system; asphalt pavement; public administration.

Resumen: En hemodiálisis, que es la filtración de impurezas sanguíneas mediante un proceso terapéutico mecánico al que están sometidas las personas con pérdida de función renal, se utiliza un gran volumen de agua, que idealmente debe ser pura, libre de agentes contaminantes. En Ilha Solteira, SP, Brasil, la unidad de hemodiálisis cuenta con 21 máquinas para realizar las sesiones y atiende a 83 pacientes. Esta investigación tuvo como objetivo evaluar la calidad del agua de hemodiálisis en el Hospital Regional de Ilha Solteira, mediante la comparación de las características presentadas, y los parámetros físico-químicos y bacteriológicos actuales del agua utilizada en el tratamiento de pacientes renales, además de observar si se están cumpliendo los aspectos legales. La metodología utilizada fue la investigación exploratoria-descriptiva con búsqueda de información bibliográfica y documental centrada en leyes y normas relacionadas con el tratamiento de agua para hemodiálisis y recolección de datos microbiológicos y físico-químicos en los registros del sector de hemodiálisis del hospital relevado en los meses de enero a diciembre de 2017. Para la recolección de datos, se definieron cuatro puntos muéstrales para el análisis. Los datos obtenidos cumplieron con el estándar para el parámetro de bacterias heterótrofas. No se detectaron impurezas en el agua observada, incluidos los coliformes termotolerantes. Los resultados físico-químicos mostraron valores compatibles con la legislación e indicaron un buen funcionamiento de la membrana de ósmosis inversa, evitando complicaciones a los pacientes

Palabras clave: sistema de gerencia de pavimentos; pavimento de asfalto; gestión pública. 


\section{INTRODUÇÃO}

A insuficiência renal crônica (IRC), também conhecida como doença renal crônica (DRC), é definida como uma síndrome metabólica que ocasiona a perda lenta, progressiva e irreversível da função renal glomerular, tubular e endócrina. Nas fases mais avançadas da doença, os rins não conseguem manter a homeostasia corporal. A doença leva ao acúmulo de líquidos e resíduos no organismo e afeta os sistemas e funções do corpo (como produção de glóbulos vermelhos e o controle da pressão arterial).

Habitualmente, a doença renal crônica ocorre associada a fatores de risco, a outra doença ou condição de saúde com danos aos rins, tendendo a agravar-se com o tempo. Entre esses fatores de risco ou doenças, estão o diabetes tipo 1 e 2, hipertensão, dificuldades com o trato urinário (como hiperplasia prostática, cálculos renais), infecção renal recorrente, lesão ou trauma nos rins e uso abusivo de anti-inflamatórios.

Assintomática na fase inicial, a insuficiência renal crônica se instala de forma lenta, e os sintomas costumam não se manifestar até que os rins comecem a ter seu funcionamento prejudicado, isto é, quando se conhece o diagnóstico, os rins estão com seu funcionamento comprometido, e a doença se apresenta em estágio avançado. Como a doença demora meses para ocorrer, o organismo se adapta ao mau funcionamento dos rins, o que torna imperceptíveis os sinais ou sintomas até a instalação definitiva da doença e, na maioria dos casos, em fase avançada, quando o paciente tende a apresentar anemia, agravamento dos valores da pressão arterial e edemas dos membros inferiores.

Pela ausência de sintomas visíveis até estágio avançado, o diagnóstico deve ser preventivo por meio de ultrassonografia dos rins para avaliar a morfologia renal e, principalmente, de análises laboratoriais, com dosagem sanguínea para verificação dos níveis de ureia e creatinina (consideradas o melhor marcador da função renal). Esses exames permitem identificar complicações renais precocemente (como grau de anemia inicial, alterações dos eletrólitos - como cálcio, fósforo e potássio -, alterações do hormônio PTH, valores de $\mathrm{pH}$ do sangue, entre outras).

O tratamento inicial da insuficiência renal crônica se faz pelo controle da pressão arterial e dieta alimentar. Pode ser incluída a ingestão de medicamentos 
especiais para impedir o acúmulo dos níveis de fósforo no sangue, tratamento para anemia com adição de ferro à dieta, uso de suplementos orais de ferro, cálcio e vitamina $D$, injeções intravenosas e transfusões de sangue.

Todavia, na maior parte dos casos, quando a doença renal crônica é diagnosticada, o paciente também pode descobrir que necessita de diálise ou hemodiálise, cuja introdução depende de fatores diversos, como resultados dos exames de laboratório, gravidade dos sintomas e disposição do paciente para as sessões. Há de se registrar que o transplante de rim ocorre como uma das últimas opções para um paciente renal crônico.

No tratamento de diálise/hemodiálise, usa-se uma grande quantidade de água, que deve ser idealmente pura, isenta de qualquer agente contaminante, isto é, deve receber tratamento excepcional e ser constantemente monitorada. A maior preocupação em relação à qualidade da água usada durante o processo refere-se aos seus parâmetros microbiológicos, físico-químicos e à presença de endotoxinas. O tratamento da água dialítica deve seguir, rigorosamente, os padrões normatizados pela legislação pertinente.

Esta pesquisa visou avaliar a qualidade da água na unidade de hemodiálise do Hospital Regional de Ilha Solteira, pela comparação das características apresentadas, e os atuais parâmetros físico-químicos e bacteriológicos da água utilizada no tratamento de pacientes renais, além de observar se as normas e os aspectos legais estão sendo cumpridos.

\section{DESENVOLVIMENTO}

Segundo o Ministério da Saúde (BRASIL, 2015), a doença renal crônica atinge $10 \%$ da população mundial e afeta homens e mulheres de todas as idades e raças. Calcula-se que a enfermidade comprometa um em cada cinco homens e uma em cada quatro mulheres com idade entre 65 e 74 anos, sendo que metade da população com 75 anos ou mais sofre algum grau da doença. Esses pacientes não podem fazer uso de água, mesmo a água potável, cujo padrão de potabilidade está estabelecido na Portaria 2.914/2011, do Ministério da Saúde, e mantida pela Portaria de Consolidação n. 5, do Ministério da Saúde (BRASIL, 2011; 2017).

A filtragem das impurezas do sangue pode ser feita de duas maneiras: pela diálise peritoneal, que aproveita a membrana peritoneal que 
reveste toda a cavidade abdominal do corpo humano para filtrar o sangue (SOCIEDADE BRASILEIRA DE NEFROLOGIA [SBN], 2020), ou pela hemodiálise, método purificador do sangue realizado por um aparelho externo, o dialisador, que retira todo o sangue do paciente, fazendo-o passar por uma filtragem e voltar ao paciente (SBN, 2019).

As sessões de hemodiálise para cada paciente dura de 3 a 5 horas, três vezes por semana, ou mesmo diariamente. O médico nefrologista avaliará o paciente para que seja escolhida a melhor forma de tratamento (SBN, 2019), quando é utilizado um grande volume de água, cerca de 120 litros por paciente, variando entre 18.000 e 36.000 litros por ano.

Moura-Neto, Barraclough e Agar (2019) reiteram que a nefrologia, com destaque para a diálise, está entre os fatores mais nocivos ao meio ambiente, e estima-se que mais de três milhões de pacientes no mundo se sujeitam à diálise de manutenção, números que tendem a mais que duplicar até 2030. Por isso, o tratamento da água não pode ser negligenciado, por ser um dos recursos mais utilizados no tratamento pela diálise e por evitar contaminação e danos.

Portanto a água é elemento essencial para diálise e deve ser de qualidade, a fim de se evitarem complicações para os pacientes. As soluções e os equipamentos utilizados para diálise proporcionam ambientes favoráveis ao desenvolvimento de microrganismos, principalmente bactérias Gram-negativas (como Enterobacter, Pseudomonas, Burkholderia, Stenotrophomonas), que são as principais responsáveis pela ocorrência de endotoxinas bacterianas (BUGNO et al., 2007).

A contaminação microbiológica da água acontece nas superfícies do sistema do tratamento hemodialítico, devido a seu fluxo contínuo, e transporta material microbiológico das tubulações para as máquinas de diálise, tais como células microbianas, endotoxinas e metabólitos microbianos que crescem dentro do equipamento (SILVA; TEIXEIRA, 2011; JESUS; CARMO; FERREIRA, 2019).

Comumente, os pacientes em diálise/hemodiálise se acham mais vulneráveis à contaminação da água e podem assimilar substâncias que colocam sua saúde em risco (COSTA; CHAVES; PEREIRA, 2018). A microbiologia da água pode demonstrar uma alta contagem de níveis de bactérias, responsáveis por reações pirogênicas e bacteremia que acometem os pacientes, em particular, a endotoxina derivada de bactérias Gram-negativas (JESUS; CARMO; FERREIRA, 2019). 
A qualidade da água que circula nos sistemas de hemodiálise, portanto, é um dos aspectos mais preocupantes no processo, porque sua situação físico-química e microbiológica inadequada pode comprometer seriamente a condição clínica do paciente hemodialítico devido aos contaminantes orgânicos ou inorgânicos nela presentes (VASCONCELOS, 2012). Logo, a qualidade da água usada no tratamento é de vital importância, porque a água compõe 95\% de toda a solução empregada na limpeza do sangue (SILVA; TEIXEIRA, 2011). Assim, as unidades de diálise/hemodiálise necessitam aplicar tratamentos específicos no sentido de adequar a água aos procedimentos hemodialíticos, conforme os parâmetros de qualidade da água constantes da Resolução RDC n. 11, da Agência Nacional de Vigilância Sanitária (BRASIL, 2014).

Para ser absolutamente pura, a água deve ser submetida a um tratamento específico realizado por aparelhos como os deionizadores, compostos de várias colunas, uma com grãos de areia de vários tamanhos, outra com carvão ativado, uma de resina catiônica, uma de resina aniônica e filtros microporosos (Figura 1).

Figura 1 - Tratamento de água para hemodiálise

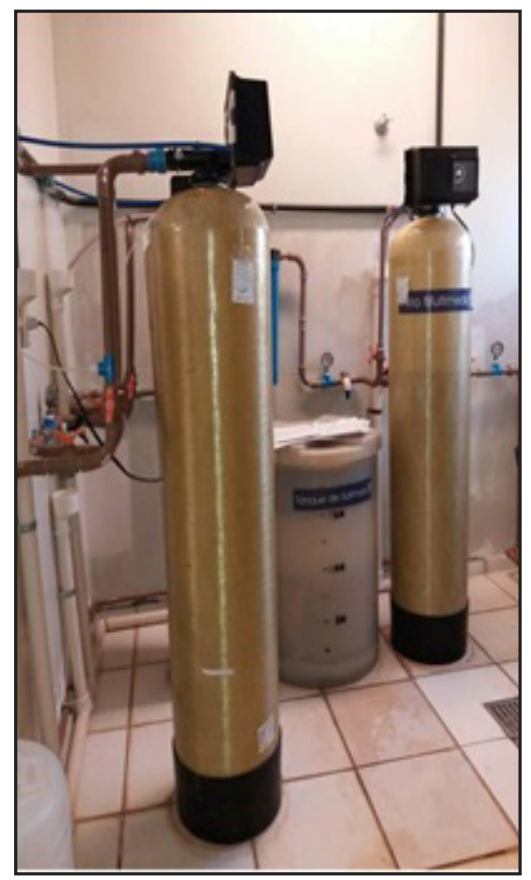

Fonte: Própria autora (2020). 
Sendo a hemodiálise um método cujo maior insumo consumido é a água, a maior preocupação relacionada à qualidade da água usada durante o processo diz respeito aos seus parâmetros microbiológicos, físico-químicos e à presença de endotoxinas.

Todo tratamento da água dialítica deve obedecer, rigorosamente, aos padrões normatizados pela Resolução da Diretoria Colegiada RDC n. 11, de 13 de março de 2014 (BRASIL, 2014).

O parágrafo único do artigo 49 da Resolução RDC 11 estabelece que a análise da água para hemodiálise deve ser realizada por laboratório analítico, licenciado junto ao órgão sanitário competente. Em sequência, seu artigo 51 estabelece que as amostras da água para hemodiálise para fins de análises microbiológicas devem ser coletadas, no mínimo, nos seguintes pontos: I - no ponto de retorno da alça de distribuição (loop); e II - em um dos pontos na sala de processamento (BRASIL, 2014).

Como a qualidade da água é uma das principais fontes de risco em sessões de hemodiálise, evidencia-se a necessidade de se conhecerem os parâmetros físico-químicos e microbiológicos da água usada em diálise/hemodiálise para prevenir a contaminação por microrganismos e complicações à saúde dos pacientes submetidos a esse tipo de tratamento.

Em Ilha Solteira, a prevenção pode ser efetiva e só obtida por uma atenção especial ao assunto. Esta é, pois, a razão desta pesquisa: avaliar a qualidade da água nessa unidade, analisar os parâmetros físico-químicos e microbiológicos da água utilizada no tratamento de pacientes renais, para atestar sua qualidade, e observar se a legislação específica é cumprida.

\section{METODOLOGIA}

\subsection{Pesquisa bibliográfica e documental}

Esta pesquisa é caracterizada como de caráter exploratório-descritivo, tendo como fundamento a busca por informações bibliográficas e documentais.

Segundo Gil (2007), a pesquisa bibliográfica contém um material conduzido, que oferece ao pesquisador um rol amplo de fenômenos estudados. Para tanto, foram selecionados artigos publicados a partir de 2005 sem, no entanto, desprezar obras com aderência ao tema publicadas em anos 
anteriores. A busca para revisão da literatura foi baseada na legislação pertinente, documentação, obras, artigos, dissertações, teses etc., servindo-se de sites governamentais e oficiais, repositórios de universidades e plataformas como a base de dados Scientific Electronic Library Online (SciELO), Base de Dados de Enfermagem (Bdenf), Literatura Latino-Americana e do Caribe em Ciências da Saúde (Lilacs), Medline, PubMed, Epub, entre outras. A busca e a seleção das obras foram realizadas no segundo semestre de 2017, entre os meses de julho e dezembro.

A pesquisa documental é, segundo Marconi e Lakatos (2007), uma fonte de coleta de dados restrita a documentos, públicos ou privados, e se constitui uma fonte primária ou um material a ser analisado, que possibilita, entre outros aspectos, análises qualitativas a respeito de determinado fenômeno e, ao mesmo tempo, análises quantitativas, com acesso a dados ou registros de informações numéricas sobre determinada situação ou tema (LOPES, 2006).

Nesse sentido, foi realizada uma pesquisa documental, destacando as leis ou normas atinentes aos objetivos desta investigação, para verificar o cumprimento da legislação referente ao tratamento da água para as sessões de hemodiálise no hospital pesquisado. Os dados microbiológicos e os dados físico-químicos da água de diálise avaliados neste trabalho foram obtidos por meio de arquivos do setor de hemodiálise do hospital, registrados nos meses de janeiro a dezembro de 2017 e cedidos pela administração.

Os dados analisados foram: concentração de bactérias heterotróficas, contagem dos ensaios de alumínio, antimônio, arsênio total, bário total, berílio total, cádmio total, cálcio, chumbo total, cloramina total, cloro residual total, cobre, condutividade, cromo total, fluoreto total, magnésio, mercúrio total, nitrato, potássio, prata total, selênio total, sódio, sulfato total, tálio e zinco total.

Como se tratou de pesquisa eminentemente bibliográfica e documental, embora tenha apresentado abordagem qualitativa, não houve necessidade de submissão ao Conselho de Ética da Instituição acadêmica, conforme disposições da Resolução n. 466/12 (BRASIL, 2012). 


\section{2 Área de estudo}

A pesquisa foi realizada na unidade de tratamento de hemodiálise do Hospital Regional no município de Ilha Solteira, Estado de São Paulo.

O Hospital Regional de Ilha Solteira é uma instituição filantrópica, sem fins lucrativos, e possui 125 leitos que atende pacientes do SUS, particulares e conveniados. É administrado pela Associação Lar São Francisco de Assis na Providência de Deus, desde janeiro de 2010. Com mais de 200 profissionais de saúde prestando atendimento, é referência para 12 municípios da região. Oferece serviço de pronto-socorro, câmara hiperbárica, tratamento de hemodiálise, atendimento ambulatorial em várias especialidades, cirurgias, parto, exames de diagnóstico, entre outros (ASSOCIAÇÃO..., s.d.).

\subsection{O serviço de hemodiálise do Hospital Regional de Ilha Solteira}

A unidade do Hospital Regional de Ilha Solteira, SP, atende 86 pacientes que necessitam de hemodiálise. O setor é dividido em duas salas: uma sala caracterizada como sala branca e outra como amarela. Na sala branca (Figura 2), em que estão instaladas 17 máquinas de hemodiálise e uma máquina de reserva para emergências, os pacientes não portadores de doenças infectocontagiosas realizam a hemodiálise. A sala amarela atende pacientes portadores de doenças infectocontagiosas; nesta sala, estão instaladas três máquinas para as sessões.

Figura 2-Sala (branca) para tratamento de diálise em Ilha Solteira

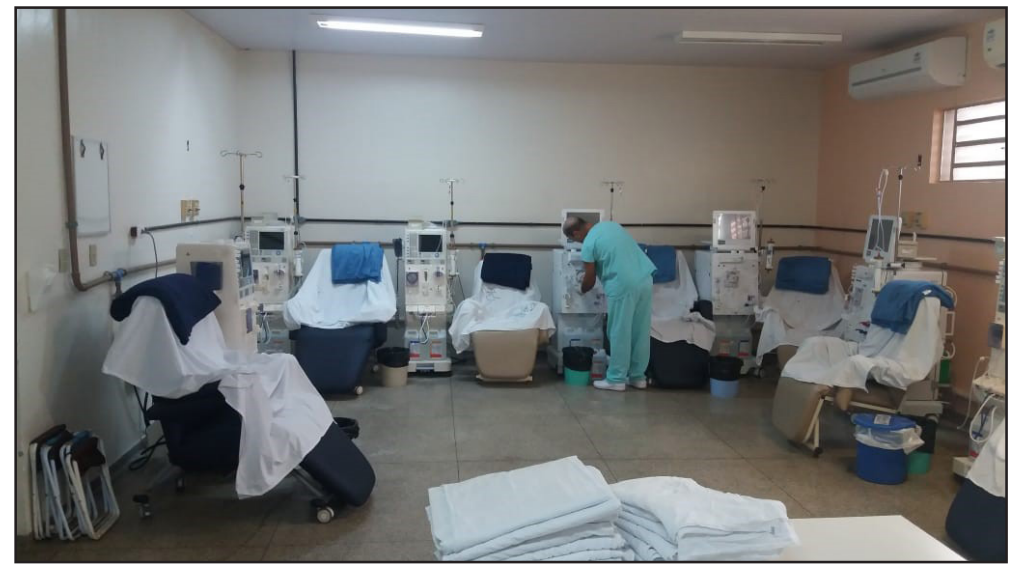

Fonte: Própria autora (2020). 
O setor possui, ainda, uma sala de reúso onde é realizada a desinfecção dos capilares, copa, sala de armários, sala de setor de limpeza, sala de emergência, sala de consultório médico, armário de prontuários, balança, mesas, pias, máquinas de hemodiálise, cadeiras de repouso para realizar as sessões, banquinho de apoio para os pés, ar-condicionado e armários de roupas.

Os horários são divididos por sessões de três ou quatro horas cada uma, das $6 \mathrm{~h} 00 \mathrm{~min}$ às $21 \mathrm{~h} 30 \mathrm{~min}$. Alguns pacientes são atendidos nas segundas, quartas e sextas-feiras, enquanto outros realizam a sessão às terças, quintas-feiras e sábados.

A equipe de profissionais é composta de dois médicos especialistas, três enfermeiras, sendo uma coordenadora e duas enfermeiras assistenciais, e vintes técnicos de enfermagem em escala de revezamento.

\subsection{Pontos de coleta de amostras de água no setor de hemodiálise}

Para fins de monitoramento, os pontos de coleta de amostras foram aqueles definidos na RDC n. 11 (BRASIL, 2014). Portanto a água utilizada em serviços de diálise deve seguir os requisitos mínimos quanto aos parâmetros químicos e microbiológicos definidos nesta lei, que dispõe sobre os requisitos de boas práticas de funcionamento para os serviços de diálise.

As amostras para esta pesquisa foram colhidas nos pontos definidos como apresentado na Tabela 1.

Tabela 1 - Descrição dos pontos de amostragem de água do setor de hemodiálise do Hospital Regional de Ilha Solteira, SP

\begin{tabular}{|c|c|c|}
\hline $\begin{array}{l}\text { Pontos de } \\
\text { amostragem }\end{array}$ & Denominação & Descrição dos pontos de amostragem \\
\hline P1 & Pré-osmose & $\begin{array}{l}\text { Água potável tratada pelo município que } \\
\text { abastece o hospital }\end{array}$ \\
\hline $\mathbf{P 2}$ & Pós-osmose & $\begin{array}{l}\text { Água potável após tratamento por } \\
\text { deionizadores, filtros mecânicos, abranda- } \\
\text { dores, filtros de carvão ativado e osmose } \\
\text { reversa }\end{array}$ \\
\hline P3 & Água tratada & $\begin{array}{l}\text { Água utilizada na lavagem do sistema de } \\
\text { diálise }\end{array}$ \\
\hline P4 & Água do dialisato & Água utilizada pelas máquinas de diálise \\
\hline
\end{tabular}
Fonte: Própria autora (2020). 
A osmose é um fenômeno físico-químico natural que ocorre quando dois líquidos com diferentes concentrações de sais em solução são separados por uma membrana semipermeável. Naturalmente, o solvente da solução mais diluída passa pela membrana em direção da concentração mais densa (concentrada). O processo continua até alcançar um ponto de equilíbrio, no qual a coluna da solução mais concentrada estará acima da mais diluída. Esta diferença de altura entre as colunas se denomina pressão osmótica (MONTEIRO, 2009).

A osmose reversa do Hospital de Ilha Solteira possui, para o tratamento de água, um abrandador, um filtro de areia e uma máquina de osmose, conforme mostra a Figura 3.

A análise da água e a manutenção dos equipamentos de tratamento de água são terceirizadas para empresas do ramo, de acordo com o Art. 17 da Portaria de Consolidação n. 5 (BRASIL, 2017).

Figura 3 - Sistema de tratamento por osmose reversa

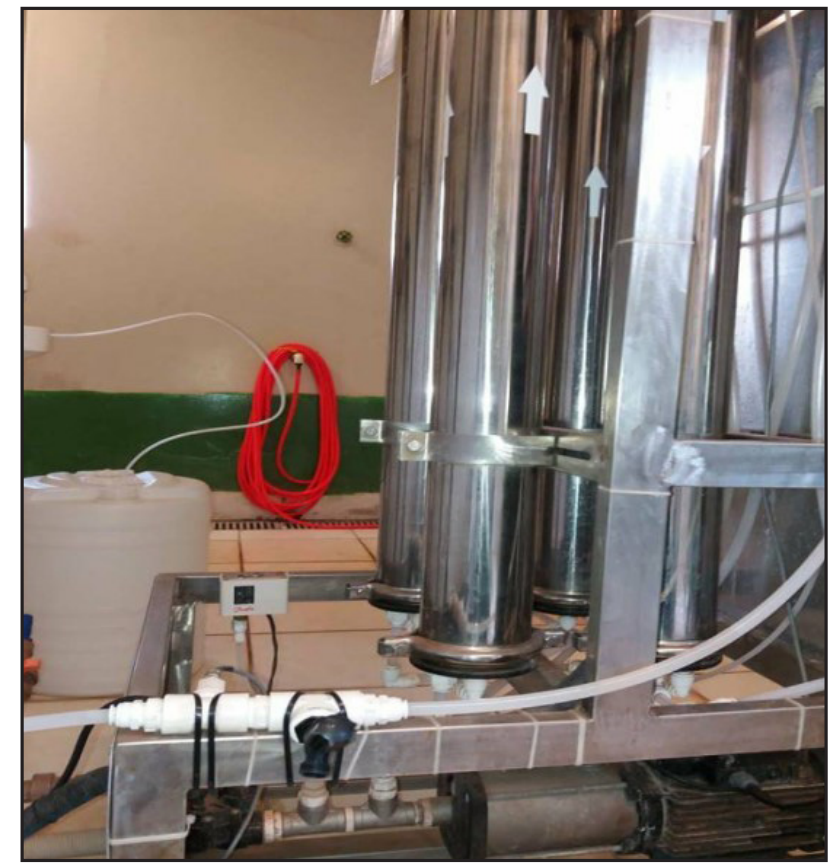

Fonte: Própria autora (2020). 
A unidade de hemodiálise de Ilha Solteira tem uma enfermeira responsável por realizar a leitura dos manômetros, testes da dureza da água, pH da água e medição do nível de cloro da água diariamente, anotando os resultados em planilhas.

No ponto de amostragem denominado de pré-osmose (P1), foram coletadas amostras de água potável tratada pelo munícipio que abastece o Hospital Regional de Ilha Solteira, SP. A água do P1 é direcionada para um processo de tratamento adequado para diálise constituído por deionizadores, filtros mecânicos, abrandadores, filtros de carvão ativado e osmose reversa. Após esse processo, tem-se o ponto de amostragem denominado pós-osmose (P2).

Os filtros mecânicos têm como função remover partículas em suspensão, enquanto os filtros de carvão ativado são utilizados para adsorver cloretos, cloraminas e substâncias orgânicas. Os abrandadores são equipamentos usados para remoção de cálcio, magnésio e outros cátions polivalentes (controle da dureza da água), além de protegerem as membranas do sistema de osmose reversa.

Os deionizadores são compostos por resinas capazes de eliminar sais minerais, matéria orgânica e partículas coloidais. A osmose reversa propicia uma água pura (MOURA et al., 2019) do ponto de vista físico, químico e microbiológico, sendo capaz de reter de $95 \%$ a $99 \%$ dos contaminantes químicos e, praticamente, todas as bactérias, fungos, algas e vírus, além de reter pirogênicos e materiais proteicos (SILVA et al., 1996).

De acordo com Ramirez (2011), o desempenho das membranas da osmose reversa precisa ser monitorado, pois uma eventual ruptura ou diminuição da sua capacidade de remoção de contaminantes microbiológicos, químicos, endotoxinas e materiais proteicos de alto peso molecular, por dano químico ou por colonização bacteriana, podem causar várias respostas fisiológicas agudas e complicações em longo prazo nos pacientes.

O terceiro ponto de amostragem, denominado de água tratada (P3), é caracterizado pela água que passou pelo sistema de tratamento realizado pelos abrandadores e osmose reversa e passa pelo sistema de reúso, que é a água empregada para lavar os capilares e circuitos utilizados para o tratamento de hemodiálise. 
No último ponto de coleta, denominado água do dialisato (P4), a amostra de água tratada é coletada em uma das máquinas de diálise. A escolha da máquina para realização da análise é aleatória, a fim de garantir a qualidade da água do sistema de tratamento, independentemente da máquina que o paciente esteja utilizando.

\section{RESULTADOS E DISCUSSÃO}

\subsection{Compreensão microbiológica da água}

De acordo com a análise da água dos quatro pontos de amostragem do setor de diálise do hospital deste estudo, foram registradas concentrações de bactérias heterotróficas abaixo de 1,0 x 102 unidades formadoras de colônias por mililitro (UFC/mL) em todos os pontos (Tabela 2).

A concentração de bactérias heterotróficas na água potável destinada para o consumo, que abastece o hospital deste estudo (P1), atende o limite estabelecido pela Portaria n. 2.914, de 12 de dezembro de 2011, que é de no máximo 5,0 x 102 UFC/mL e mantido pela Portaria de Consolidação n. 5 (BRASIL, 2017).

Segundo a RDC n. 11/2014 (BRASIL, 2014), a água utilizada para preparação de solução de diálise deve apresentar, como valor do parâmetro máximo permitido, 200 (duzentos) UFC/ml e o nível de ação de 50 (cinquenta) UFC/ml.

Verificou-se no presente estudo que, em todos os pontos de amostragem, a água atendeu o padrão estabelecido para o parâmetro de bactérias heterotróficas.

Tabela 2 - Concentração de bactérias heterotróficas (UFC/ML) nos pontos de amostragem de água do setor de hemodiálise do Hospital Regional de Ilha Solteira, nos meses de janeiro a dezembro de 2017

\begin{tabular}{ccccc}
\hline \multirow{2}{*}{ Meses de avaliação } & \multicolumn{5}{c}{ Pontos de amostragem } \\
\cline { 2 - 5 } & $\mathbf{P 1}$ & $\mathbf{P 2}$ & $\mathbf{P 3}$ & $\mathbf{P 4}$ \\
\hline Janeiro & $<1,0 \times 10^{2}$ & $<1,0 \times 10^{2}$ & $<1,0 \times 10^{2}$ & $<1,0 \times 10^{2}$ \\
Fevereiro & $<1,0 \times 10^{2}$ & $<1,0 \times 10^{2}$ & $<1,0 \times 10^{2}$ & $<1,0 \times 10^{2}$ \\
Março & $<1,0 \times 10^{2}$ & $<1,0 \times 10^{2}$ & $<1,0 \times 10^{2}$ & $<1,0 \times 10^{2}$ \\
Abril & $<1,0 \times 10^{2}$ & $<1,0 \times 10^{2}$ & $<1,0 \times 10^{2}$ & $<1,0 \times 10^{2}$
\end{tabular}




\begin{tabular}{ccccc}
\hline \multirow{2}{*}{ Meses de avaliação } & \multicolumn{5}{c}{ Pontos de amostragem } \\
\cline { 2 - 5 } & $\mathbf{P 1}$ & $\mathbf{P 2}$ & $\mathbf{P 3}$ & $\mathbf{P 4}$ \\
\hline Maio & $<1,0 \times 10^{2}$ & $<1,0 \times 10^{2}$ & $<5,0 \times 10^{2}$ & $<1,0 \times 10^{2}$ \\
Junho & $<1,0 \times 10^{2}$ & $<1,0 \times 10^{2}$ & $<1,0 \times 10^{2}$ & $<1,0 \times 10^{2}$ \\
Julho & $<1,0 \times 10^{2}$ & $<1,0 \times 10^{2}$ & $<1,0 \times 10^{2}$ & $<1,0 \times 10^{2}$ \\
Agosto & $<1,0 \times 10^{2}$ & $<1,0 \times 10^{2}$ & $<1,0 \times 10^{2}$ & $<1,0 \times 10^{2}$ \\
Setembro & $<1,0 \times 10^{2}$ & $<1,0 \times 10^{2}$ & $<1,0 \times 10^{2}$ & $<1,0 \times 10^{2}$ \\
Outubro & $<1,0 \times 10^{2}$ & $<1,0 \times 10^{2}$ & $<1,0 \times 10^{2}$ & $<1,0 \times 10^{2}$ \\
Novembro & $<1,0 \times 10^{2}$ & $<1,0 \times 10^{2}$ & $<1,0 \times 10^{2}$ & $<1,0 \times 10^{2}$ \\
Dezembro & $<1,0 \times 10^{2}$ & $<1,0 \times 10^{2}$ & $<1,0 \times 10^{2}$ & $<1,0 \times 10^{2}$ \\
\hline
\end{tabular}

Fonte: Hospital Regional de Ilha Solteira: arquivos do setor de hemodiálise (2018).

Não foi detectada a presença de coliformes termotolerantes nas amostras de água de abastecimento do hospital (P1) e nas amostras coletadas durante o processo de tratamento da água e das máquinas. Caso fosse detectada a presença desse grupo de microrganismos (coliformes fecais), seria um indicativo de contaminação fecal que poderia comprometer a saúde dos pacientes (BRASIL, 2004). Os resultados favoráveis das amostras desta pesquisa mostram a efetividade da limpeza e desinfecção dos equipamentos e das tubulações que transportam a água utilizada na diálise.

Segundo o artigo 52 da RDC n. 11/2014 (BRASIL, 2014), deve ser verificada a qualidade bacteriológica da água para hemodiálise toda vez que ocorrerem manifestações pirogênicas, bacteremia ou suspeitas de septicemia nos pacientes.

Também não foi detectada a presença de coliformes totais nas amostras de água de abastecimento do hospital (P1) e nas amostras coletadas durante o processo de tratamento da água e das máquinas. Durante o tratamento da água no processo utilizado pelo hospital, não houve contaminação por esse grupo de microrganismos, tampouco na água empregada para lavagem do material utilizado na hemodiálise dos pacientes.

\subsection{Análise físico-química da água}

A coleta da água no ponto de amostragem P2 (pós-osmose: água potável após o tratamento por deionizadores, filtros mecânicos, abrandadores, filtros de carvão ativado e osmose reversa), nos meses de maio e novembro, 
foi realizada semestralmente por um laboratório terceirizado para análise de água, A3Q, contratado pelo Hospital Regional, que coleta a água no setor de diálise e analisa as concentrações físico-químicas na água seguindo padrões da RDC n. 11/2014 (BRASIL, 2014).

A Tabela 3 apresenta os resultados da análise físico-química realizada nos pontos de amostragem do setor de hemodiálise do Hospital Regional de Ilha Solteira, SP.

Tabela 3 - Análise físico-química $(\mathrm{mg} / \mathrm{ml}$ ) no ponto de amostragem de água do setor de hemodiálise do Hospital Regional de Ilha Solteira, SP

\begin{tabular}{|c|c|c|c|}
\hline $\begin{array}{c}\text { Análises } \\
\text { físico-químicas }\end{array}$ & $\begin{array}{c}\text { Maio } \\
\text { P1 }\end{array}$ & $\begin{array}{c}\text { Novembro } \\
\text { P2 }\end{array}$ & Valor máximo permitido \\
\hline Alumínio & $<0,024 \mathrm{mg} / \mathrm{l}$ & $<0,007 \mathrm{mg} / \mathrm{l}$ & $0,01 \mathrm{mg} / \mathrm{l}$ \\
\hline Antimônio & $<0,001 \mathrm{mg} / \mathrm{l}$ & $<0,001 \mathrm{mg} / \mathrm{l}$ & $0,006 \mathrm{mg} / \mathrm{l}$ \\
\hline Arsênio total & $<0,001 \mathrm{mg} / \mathrm{l}$ & $<0,001 \mathrm{mg} / \mathrm{l}$ & $0,005 \mathrm{mg} / \mathrm{l}$ \\
\hline Bário total & $<0,0017 \mathrm{mg} / \mathrm{l}$ & $<0,0017 \mathrm{mg} / \mathrm{l}$ & $0,1 \mathrm{mg} / \mathrm{l}$ \\
\hline Berílio total & $<0,0004 \mathrm{mg} / \mathrm{l}$ & $<0,0004 \mathrm{mg} / \mathrm{l}$ & $0,0004 \mathrm{mg} / \mathrm{l}$ \\
\hline Cádmio total & $<0,001 \mathrm{mg} / \mathrm{l}$ & $<0,001 \mathrm{mg} / \mathrm{l}$ & $0,001 \mathrm{mg} / \mathrm{l}$ \\
\hline Cálcio & $<0,156 \mathrm{mg} / \mathrm{l}$ & $<0,156 \mathrm{mg} / \mathrm{l}$ & $2 \mathrm{mg} / \mathrm{l}$ \\
\hline Chumbo total & $<0,005 \mathrm{mg} / \mathrm{l}$ & $<0,005 \mathrm{mg} / \mathrm{l}$ & $0,005 \mathrm{mg} / \mathrm{l}$ \\
\hline Cloramina total & $<0,04 \mathrm{mg} / \mathrm{l}$ & $<0,04 \mathrm{mg} / \mathrm{l}$ & $0,1 \mathrm{mg} / \mathrm{l}$ \\
\hline $\begin{array}{l}\text { Cloro residual } \\
\text { total (combinado } \\
+ \text { livre), água }\end{array}$ & $<0,04 \mathrm{mg} / \mathrm{l}$ & $<0,04 \mathrm{mg} / \mathrm{l}$ & $\begin{array}{c}\text { Água da rede pública maior } \\
\text { que 0,2 mg/L; água de fonte } \\
\text { alternativa: maior que Diária } \\
\text { 0,5 mg/l }\end{array}$ \\
\hline Cobre & $<0,011 \mathrm{mg} / \mathrm{l}$ & $<0,011 \mathrm{mg} / \mathrm{l}$ & $0,1 \mathrm{mg} / \mathrm{l}$ \\
\hline Condutividade & $4,70 \mathrm{uS} / \mathrm{cml}$ I & $12,73 \mathrm{uS} / \mathrm{cml}$ & $4,70 \mathrm{uS} / \mathrm{cml}$ \\
\hline Cromo total & $<0,008 \mathrm{mg} / \mathrm{l}$ & $<0,008 \mathrm{mg} / \mathrm{l}$ & $0,014 \mathrm{mg} / \mathrm{l}$ \\
\hline Fluoreto total & $<0,15 \mathrm{mg} / \mathrm{l}$ & $<0,15 \mathrm{mg} / \mathrm{l}$ & $0,2 \mathrm{mg} / \mathrm{l}$ \\
\hline Magnésio & $<0,06 \mathrm{mg} / \mathrm{l}$ & $<0,06 \mathrm{mg} / \mathrm{l}$ & $4 \mathrm{mg} / \mathrm{l}$ \\
\hline Mercúrio total & $<0,0001 \mathrm{mg} / \mathrm{l}$ & $<0,0001 \mathrm{mg} / \mathrm{l}$ & $0,0002 \mathrm{mg} / \mathrm{l}$ \\
\hline Nitrato & $0,50 \mathrm{mg} / \mathrm{l}$ & $0,50 \mathrm{mg} / \mathrm{l}$ & $2 \mathrm{mg} / \mathrm{l}$ \\
\hline Potássio & $<0,158 \mathrm{mg} / \mathrm{l}$ & $<0,158 \mathrm{mg} / \mathrm{l}$ & $8 \mathrm{mg} / \mathrm{l}$ \\
\hline Prata total & $<0,005 \mathrm{mg} / \mathrm{l}$ & $<0,005 \mathrm{mg} / \mathrm{l}$ & $0,005 \mathrm{mg} / \mathrm{l}$ \\
\hline Selênio total & $<0,001 \mathrm{mg} / \mathrm{l}$ & $<0,001 \mathrm{mg} / \mathrm{l}$ & $0,09 \mathrm{mg} / \mathrm{l}$ \\
\hline Sódio & 0,719 mg/l & $1,360 \mathrm{mg} / \mathrm{l}$ & 70 mg/l \\
\hline Sulfato total & $8,29 \mathrm{mg} / \mathrm{l}$ & $<0,30 \mathrm{mg} / \mathrm{l}$ & $100 \mathrm{mg} / \mathrm{l}$ \\
\hline Tálio & $<0,002 \mathrm{mg} / \mathrm{l}$ & $<0,002 \mathrm{mg} / \mathrm{l}$ & 0,002 mg/l \\
\hline Zinco total & 0,061 mg/l & $<0,011 \mathrm{mg} / \mathrm{l}$ & $0,1 \mathrm{mg} / \mathrm{l}$ \\
\hline
\end{tabular}

Fonte: Hospital Regional de Ilha Solteira: arquivos do setor de hemodiálise (2018). 
O Anexo XX da portaria estabelece o controle e a vigilância da qualidade da água para consumo humano e seu padrão de potabilidade, trazendo em seu texto (BRASIL, 2017): “Artigo 1ㅇ․ Esta Portaria dispõe sobre os procedimentos de controle e de vigilância da qualidade da água para consumo humano e seu padrão de potabilidade".

Destaca-se que, neste estudo, não houve alteração nos parâmetros e nas concentrações máximas permitidas (Tabela 3). Buzzo et al. (2010) ressaltam a importância da implantação de um programa de monitoramento da água tratada nos serviços de diálise, para inspecionar os serviços de saúde prestados à população, avaliar amostras coletadas nos pontos definidos na legislação e reduzir os riscos dialíticos.

É valido lembrar a importância do controle da qualidade da água aplicada na hemodiálise. Em 1996, na cidade de Caruaru, PE, mais de 100 pacientes renais crônicos que eram submetidos ao tratamento de hemodiálise no Instituto de Doenças Renais (IDR) morreram vítimas da água contaminada que fazia a filtragem do sangue dos doentes. A causa, identificada como Microsystina LR (cianobactéria), só foi descoberta 52 dias depois de 38 pessoas irem a óbito. Estudos realizados na barragem Tabocas mostraram que os caminhões-pipa costumavam extrair a água do manancial para a clínica, localizada no bairro Maurício de Nassau. Esse caso mobilizou pesquisadores do mundo inteiro e ficou conhecido como a Tragédia da Hemodiálise de Caruaru (BARBOSA, 2016).

Após essa tragédia, a análise de cianobactérias em águas utilizadas em clínicas de hemodiálise passou a ser uma exigência legal - Portaria Ministério da Saúde, n. 2.914, de 12 de dezembro de 2011 (BRAIL, 2011). No presente trabalho, não foi detectada a presença de toxinas produzidas por cianobactérias na água utilizada para o tratamento dos pacientes com doenças renais.

Msagati, Siame e Shushu (2006) e Sanches et al. (2007) apontam que algumas cepas de algas, em especial as do grupo cianofíceas ou cianobactérias, podem produzir toxinas devido à morte ou lise celular e podem lesar o fígado (hepatoxinas) e o sistema nervoso (neurotoxinas), ou somente irritar a pele. Para Moreno et al. (2005) e Sanches et al. (2007), as cianobactérias podem apresentar gosto e odor desagradáveis na água, porém 
o maior problema está no fato de que produzem toxinas, as microcistinas, que podem provocar intoxicação e morte de seres humanos e de animais. Segundo Chen et al. (2006) e Sanches et al. (2007), as microcistinas são muito resistentes a altas temperaturas e mantêm a toxicidade mesmo após a fervura, podendo levar indivíduos a uma maior incidência de câncer hepático e, até mesmo, a óbito.

De acordo com a análise da água do ponto de amostragem P2 (pós-osmose) do setor de diálise do Hospital Regional, realizada nos meses de maio e novembro, não foram registradas alterações nas concentrações químicas, pois as concentrações atendem o limite estabelecido pela RDC n. $11 / 2014$. A condutividade da água no mês de novembro apresentou 12,73 uS/cml, cujo valor máximo permitido pela lei é de 4,70 uS/cml (BRASIL, 2014).

Simões et al. (2005) afirmam que pequenas variações na condutividade da água tratada podem indicar variações na qualidade da água que abastece o sistema de tratamento. Grandes variações na condutividade podem indicar um problema na membrana da osmose reversa, como o seu rompimento. Portanto, quanto mais pura uma água do ponto de vista físico-químico, menor será sua condutividade.

A hemodiálise é uma terapia que consome uma grande quantidade de água, a qual, se devidamente tratada, produzirá impacto ambiental mínimo (AGAR, 2012). É uma água altamente filtrada e apresenta condutividade ligeiramente superior à da água mineral comercialmente consumida, além de ter gosto indistinguível.

\section{CONCLUSÃO}

No tratamento, os usuários dos serviços de hemodiálise estão expostos a riscos. É necessário que medidas de segurança nesse ambiente de tratamento sejam implantadas para que alguns riscos sejam minimizados.

A água que abastece o Hospital Regional de Ilha Solteira, SP, assim como a água que passa pelo tratamento do hospital para ser utilizada na diálise de pessoas com doença renal crônica, apresenta qualidade microbiológica adequada para sua finalidade. 
Do ponto de vista físico-químico e microbiológico, os resultados das amostras coletadas nos pontos de amostragem apresentaram valores permitidos pela legislação.

Esses valores apontam se a membrana da osmose reversa funciona com qualidade adequada, evitando, assim, complicações aos pacientes. Por essa razão, a análise da água do setor de hemodiálise, tanto microbiológica quanto físico-química, mostra-se tão importante.

Os resultados desta pesquisa mostraram que a unidade de hemodiálise do hospital pesquisado cumpre a legislação quanto aos cuidados exigidos para o tratamento de pacientes renais e lhes garante a qualidade necessária para a inexistência de riscos relativos ao uso da água quando expostos ao tratamento.

\section{AGRADECIMENTOS}

Aos administradores do Hospital Regional de Ilha Solteira, Fabiana Belini e Frei Jessé, pelo fornecimento de dados da água do setor da Hemodiálise do Hospital Regional de Ilha Solteira, SP. Aos médicos nefrologistas responsáveis pelo setor, Dr. Emanuel Wendeborn Zinezi Rodrigues e Reinaldo Ferreira Carlessi.

\section{REFERÊNCIAS}

AGAR, J. W. M. Personal viewpoint: hemodialysis - water, power, and waste disposal: rethinking our environmental responsibilities. Hemodialysis International, v. 16, n. 1, p. 6-10, jan. 2012.

BARBOSA, H. A tragédia da hemodiálise de Caruaru 20 anos depois [on-line], 25 fev. 2016. Disponível em: http://henriquebarbosa.com/2016/02/25/tragedia-dahemodialise-de-caruaru-20-anos-depois. Acesso em: 20 out. 2019.

BRASIL. Portaria de Consolidação n. 5, de 28 de setembro de 2017. Consolidação das normas sobre as ações e os serviços de saúde do Sistema Único de Saúde. Diário Oficial da União, n. 190 (supl.), de 3 outubro de 2017. Brasília, DF, 2017.

BRASIL. Ministério da Saúde. Você sabe o que é insuficiência renal? Blog da Saúde, Brasília-DF, nov. 2015. Disponível em: http://www.blog.saude.gov.br/index.php/ 
promocao-da-saude/50376-voce-sabe-o-que-e-insuficiencia-real. Acesso em: 15 out. 2019.

BRASIL. Ministério da Saúde. Agência Nacional de Vigilância Sanitária (Anvisa). Resolução RDC n. 11, de 13 de março de 2014. Dispõe sobre os requisitos de boas práticas de funcionamento para os serviços de diálise e dá outras providências. Diário Oficial da União, de 14 de março de 2014, n. 50, Seção 1, p. 40-2. Brasília, DF, 2014.

BRASIL. Conselho Nacional da Saúde. Resolução 466/12, de 12 de dezembro de 2012. Aprova as diretrizes e normas regulamentadoras de pesquisas envolvendo seres humanos. Brasília: CNS, 2012.

BRASIL. Ministério da Saúde. Portaria n. 2914, de 12 de dezembro de 2011. Dispõe sobre os procedimentos de controle e de vigilância da qualidade da água para consumo humano e seu padrão de potabilidade. Diário Oficial da União, de 14 de dezembro de 2011. Brasília, DF, 2011.

BUGNO, A.; ALMODÓVAR, A. A. B.; PEREIRA, T. C.; AURICCHIO, M. T. Detecção de bactérias Gram-negativas não fermentadoras em água tratada para diálise. Revista do Instituto Adolfo Lutz, São Paulo, v. 66, n .2, p. 172-5, 2007.

BUZZO, M. L.; BUGNO, A.; ALMODÓVAR, A. A. B.; KIRA, C. S.; CARVALHO, M. F. H.; SOUZA, A. de; SCORSAFAVA, M. A. A importância de programas de monitoramento da qualidade da água para diálise na segurança dos pacientes. Revista do Instituto Adolfo Lutz, São Paulo, v. 69, n. 1, p. 1-6, 2010.

CHEN, T.; CUI, J.; LIANG, Y.; XIN, X.; YOUNG, D. O.; CHEN, C.; SHEN, P. Identification of liver mitochondrial aldehyde dehydrogenase as a potential target for microcystinLR. Toxicology, Ireland, v. 220, 2006.

COSTA, M. L. A.; CHAVES, A. R.; PEREIRA, A. A. Avaliação da qualidade da água de hemodiálise em uma unidade de diálise localizada em Belo Horizonte, MG. In: CONGRESSO BRASILEIRO DE GESTÃO AMBIENTAL, 9., São Bernardo do Campo, SP, de 26 a 29 nov. 2018. Anais [...]. São Bernardo do Campo: Instituto Brasileiro de Estudos Ambientais (Ibeas), 2018.

GIL, A. C. Métodos e técnicas de pesquisa social. 5. ed. São Paulo: Atlas, 2007.

ASSOCIAÇÃO E FRATERNIDADE SÃO FRANCISCO DE ASSIS NA PROVIDÊNCIA DE DEUS. Hospital Regional de llha Solteira. Nossas obras. [S.d.]. Disponível em: http:// www.franciscanosnaprovidencia.org.br/associacao/nossasobras_detalhes/30/ Hospital-Regional-de-Ilha-Solteira. Acesso em: 20 maio 2019. 
JESUS, P. R.; CARMO, J. S.; FERREIRA, J. A. B. Avaliação microbiológica da água utilizada nos serviços de hemodiálise na cidade do Rio de Janeiro nos anos 2016 a 2018. Vigilância Sanitária em Debate, v. 7, n. 1, p. 53-9, 2019.

LOPES, J. Fazer do trabalho científico em ciências sociais aplicadas. Recife: UFPE, 2006.

MARCONI, M. A.; LAKATOS, E. M. Técnicas de pesquisa. 6. ed. São Paulo: Atlas. 2007.

MONTEIRO, G. S. Arranjos de membranas de osmose inversa: avaliação e comparação do desempenho de pequenos sistemas. 2009. 82f. Dissertação (Mestrado em Engenharia Química) - Programa de Pós-Graduação em Engenharia Química, Universidade Federal de Campina Grande, Campina Grande, Paraíba, 2009.

MORENO, I.; PICHADRO, S.; JOS, A.; GOMES-AMORES, L.; MATE, A.; VASQUEZ, C. M.; CARMEÁN, A. M. Antioxidant enzyme activity and lipid peroxidation in liver and kidney of rats exposed to microcystin-LR administered intraperitoneally. Toxicon, v. 45, n. 4, p. 395-402, mar. 2005.

MOURA, J. P.; MONTEIRO, G. S.; SILVA, J. N.; PINTO, F. A.; FRANÇA, K. P. Aplicações do processo de osmose reversa para o aproveitamento de água salobra do semiárido nordestino. Universidade Federal de Campina Grande (UFCG), Laboratório de Dessalinização (Labdes). Revista Águas subterrâneas, Campina Grande, v. 33, n. 4, 2019.

MOURA-NETO, J. A.; BARRACLOUGH, K.; AGAR, J. W. M. Um apelo pela sustentabilidade na diálise no Brasil. Brazilian Journal of Nephrology. São Paulo, v. 41, n. 4, out./dez. 2019.

MSAGATI, T. A. M.; SIAME, B. A.; SHUSHU, D. D. Evaluation of methods for the isolation, detection and quantification of cyanobacterial hepatotoxins. Aquatic Toxicology, v. 78, n. 4, p. 382-97, jul. 2006.

RAMIREZ, S. S. Avaliação do impacto da qualidade da água em parâmetros laboratoriais indicativos de bem-estar clínico de pacientes submetidos à hemodiálise no estado do Rio de Janeiro. 2011. 74f. Dissertação (Mestrado em Vigilância Sanitária) - Instituto Nacional de Controle de Qualidade em Saúde, Fundação Oswaldo Cruz, Rio de Janeiro, RJ, 2011.

SANCHES, S. M.; VIEIRA, E. M.; PRADO, E. L.; BENETTI, F.; TAKAYANAGUI, A. M. $M$. Estudo da presença da toxina microcistina-LR em água utilizada em clínica de hemodiálise e validação de um método analítico. Eclética Química, São Paulo, v. 32, n. 4, p. 43-8, 2007. 
SILVA, A. M. M.; MARTINS, C. T. B.; FERRABOLI, R.; JORGETTI, V.; ROMÃO JÚNIOR, J. E. Revisão/Atualização em diálise: água para hemodiálise. Jornal Brasileiro de Nefrologia, v. 18, n. 2, p. 180-8, 1996.

SILVA, P. B.; TEIXEIRA, E. P. Reúso da água do rejeito de um tratamento de osmose reversa de uma unidade de hemodiálise hospitalar: estudo de caso. Revista Brasileira de Inovação Tecnológica em Saúde, v. 4, n. 4, p. 42-51, set. 2011.

SIMÕES, M.; BRÍGIDO, B. M.; MAZON, E. M. A.; PIRES, M. F. C. Água de diálise: parâmetros físico-químicos na avaliação do desempenho das membranas de osmose reversa. Revista do Instituto Adolfo Lutz (Impresso), v. 64, n. 2, p. 73-178, 2005.

SOCIEDADE BRASILEIRA DE NEFROLOGIA. O que é hemodiálise. SBN, 2019 Disponível em: https://sbn.org.br/publico/tratatamentos/hemodialise. Acesso em: 20 out. 2019.

SOCIEDADE BRASILEIRA DE NEFROLOGIA. Diálise peritoneal. SBN, 2020 Disponível em: https://sbn.org.br/publico/tratatamentos/dialise-peritoneal. Acesso em: 19 fev. 2020.

VASCONCELOS, P. D. S. de. Monitoramento da água de diálise: um estudo de caso em uma clínica do município de Recife. 2012. 110f. Monografia (Especialização em Gestão de Sistemas e Serviços de Saúde) - Centro de Pesquisa Aggeu Magalhães, Fundação Oswaldo Cruz, Recife, PE, 2012 
